\title{
The Effect of Using Attack and Indirect Counter-Attack as a Performance Effectiveness Indicator of the Kumite Players
}

\author{
Mahmoud Rabie EI Beshehy*
}

\section{Introduction and Problem of the Research}

$\mathrm{T}$ he Karate is one of the sports where many scientist and specialists endeavour to develop its technical and tactical level by means of the latest technology in analysis and training in the field of the game. This would lead researchers to jump into scientific research for the development and progress of the game's level and always improve the players' performance in order to achieve the best possible results in the international and global events.

As the Kumite has an ever-changing performance during the match, in terms of attack, counter-attack and defence processes, according to the match' various situations, compelling the player to resort to different technical styles whether to attack, directly and indirectly, and to use individual and complex skills of the body's members at the different spots of the court. Based on his academic and applied experience and pursuing several local and international tournaments of the local and international Egyptian players, the researcher noticed that the Egyptian players count on the direct attack, which requires an effort for both attack or counter-attack processes. This made the players resort to considerable performance and physical skills without receiving any technical benefits or points compared to the amount of physical, skills and tactical efforts exerted by the players. Hence, they win the matches, as they depend only on direct attack. Upon watching the world's champions, and analyzing their performance, the researcher pointed out that they depend in $75 \%$ of their technical and tactical performance on attack and

* Teacher, Physical Training Section, Faculty of Physical Education, Damietta University, Egypt. individual and complex indirect counter-attack, which helps a lot in scoring points and winning the match with less physical, skills and tactical effort than the Egyptian players who depend on huge physical, skills and tactical effort to achieve the technical points and win the matches.

Whereas developing the use of attack and individual and complex indirect counter-attack is one of the basic requirements for skills and tactical performance in view of the great effect thereof on the players' effective performance; which can be reached through analysis and practice of tactical skills performance for attack and direct and indirect counter- attack based on scientific principles in their training programs.

\section{Objectives of the Research}

The research aims at:

Identifying the effect of using attack and indirect counter-attack as a performance indicator of the Kumite player through:

1. Identifying the most used attack and individual and complex counter-attack skills by analyzing the matches;

2. Designing organized training programs using attack and individual and complex indirect counter-attack;

3. Identifying the effect of using attack and indirect counter-attack on the effectiveness of the Kumite players' skills performance;

4. Identifying the improvement rate noticed on the level of attack and indirect counter-attack skills and some elements of the Kumite players' physical fitness. 
1. There are statistically indicative differences between the average scores of both pre- and post-measurement of the empirical group in terms of the level of the physical fitness' elements [under consideration) and the individual and complex attack and indirect counter-attack skills [under consideration) and the effectiveness of skills performance favouring the post-measurement.

2. There are statistically indicative differences between the pre- and post-measurement of the adjusting group in terms of the level of the physical fitness' elements [under consideration) and the individual and complex attack and indirect counter-attack skills [under consideration) and the effectiveness of skills performance favouring the post-measurement.

3. There are statistically indicative differences between the averages of both pre- and postmeasurements of the empirical group and the adjusting group in terms of the physical fitness' elements (under consideration) and the individual and complex attack and indirect counter-attack skills [under consideration) and the effectiveness of skills performance favouring the empirical group.

4. There are differences in the improvement rate between the empirical and adjusting groups in terms of the physical fitness' elements [under consideration) and the individual and complex attack and indirect counter-attack skills (under consideration) and the effectiveness of skills performance favouring the empirical group.

\section{Procedures of the Research}

\section{Methodology of the Research}

The researcher used the empirical method using the empirical design of two groups: one empirical and the other one adjusting, by means of pre- and post-measurement for each group, being adequate to the nature of the research.

\section{Community of the Research}

The community of the research was selected among the first class players [men + ladies) at the Military Production Club, registered at the
Egyptian Karate Federation for 2011-2012 season, and specialized in Kumite.

\section{Sample of the Research}

A sample consisting of 20 male and female players were intentionally selected amidst the community of the research; they were split into two equal groups in terms of age, weight and training age, being 10 players in each group.

\section{The empirical group}

Consisting of 10 players: the researcher applied the specific suggested program [aiming at developing the individual and complex attack and indirect counter-attack).

\section{The adjusting group}

Consisting of 10 players: the program adopted at the club was applied on them [the traditional program aiming at developing the attack and indirect counter-attack).

\section{Terms of the Research}

Attack: All moves and styles used by the player to score points or obtain benefits for his favour to beat his opponent in compliance with the rules of the game. [10:3)

- Counter-attack: A reaction to the opponent's attack, be it direct or indirect, using one of the following styles:

- Sen-no-sen: Simultaneous attack against the opponent's attack, o Go-no-sen: Attack following defence against the opponent's attack, o Tai-no-sen: Attack prior to the opponent's attack. (Procedural definition)

- Indirect counter-attack: Sherif El Awady and Omar Labib provide the definition of this term being the use by the player of auxiliary skills against the opponent; such skills do not ensure scoring any points, yet they help the basic skills in scoring points [10:5)

- Complex skills: A set of skills, using arms, legs or both, by means of attack or direct or indirect counter-attack. [Procedural definition)

- Technical performance Effectiveness: Extent of the skills' similarity and symmetry to the most scientific logical and rational tactics 
[series) and are linked to the score. [Procedural definition)

\begin{tabular}{|c|c|c|c|}
\hline S & $\begin{array}{c}\text { Phases of the } \\
\text { Program/Parts }\end{array}$ & First Phase & Second Phase \\
\hline 1 & Objective & $\begin{array}{c}\text { Development of the physical } \\
\text { fitness, the skills and tactical } \\
\text { performance during attack and } \\
\text { indirect counter-attack in a } \\
\text { balanced way to help players } \\
\text { achieve the physical fitness. }\end{array}$ & $\begin{array}{c}\text { High development of technical } \\
\text { and tactical skills, to be linked } \\
\text { to performance during } \\
\text { conditional and free matches to } \\
\text { help players achieve a high } \\
\text { effectiveness, tactical and } \\
\text { physical level and improve their } \\
\text { skills and matches performance } \\
\text { effectiveness. - Maintain the } \\
\text { players' physical fitness ratio. }\end{array}$ \\
\hline 2 & Duration & 4 weeks & 4 weeks \\
\hline 3 & Practice days per week & 3 units & 3 units \\
\hline 4 & Units per day & 1 unit & From 90 to 12 min. \\
\hline 5 & $\begin{array}{c}\text { Average unit time of } \\
\text { training }\end{array}$ & From 90 min. & \\
\hline
\end{tabular}

\section{Results Discussion}

In the light of table (1) the arithmetic mean and standard deviation of the pre and post measurement, the rate of change is variable effectiveness and performance as well as the physical variable as the rate of change ranged between $50.59 \%$ as far as the variable "reaction of complex skills " is concerned. The researcher find that this variable makes the highest change percentage since reaction in complex skills is considered an important element in karate where it is used by players in kumite movements. The element depends on the reaction speed, and the researcher was concerned with developing it in training program because of its importance in karate .this according with studies Mohamed saeid abo elnor 2002, Ibrahim ali alebiary 2003, and said gameel elashker2010,

As can be seen from table ( 2 ) there were statistically significant differences between the dimentional measurement for the experimental group on one side, and that for the control group on the other in some physical and skill variables, due to the fact that both groups are subject to the training program .the differences were in favor of the experimental group in the variables associated with the karate skills as complex skills reaction, aspirate and the speed in skill performans.this according with Mohamed samir sabahy 2005, Mohamed abd elrahman 2009, and mootaz hlal abo elasaad 2010 .

As for table (6) it shows significant statistic differences between the dimensional measurements for both the experimental and control group in favor of the experimental group in the performance effectiveness. The researcher believes that the differences are in favor of the experimental group, as it used the proposed training program and what it included of exercises developing various skills, the thing that affected the speed of the strikes, and added to the effectiveness of the complex skills. This according with studies Ibrahim ali alebiary 2007, mahmoud rabie elbeshehy 2005, Hamilton roschel 2009.and Mohamed ramzy fetouh 2011. 
Table (1)

Table (1) shows the arithmetic mean, standard deviation, Variance Skewness and Kurtosis of the experimental group and the ratio of change between before \& after the Implementation

\begin{tabular}{|c|c|c|c|c|c|}
\hline \multirow{2}{*}{ Variables } & \multicolumn{2}{|c|}{ Before the implementation } & \multicolumn{2}{|c|}{ After the implementation } & \multirow{2}{*}{ Ratio Change $\%$} \\
\hline & Mean & Std. Deviation & Mean & Std. Deviation & \\
\hline Gyaku -zuki 10sec & 15.3000 & .48305 & 16.5000 & .84984 & 7.84 \\
\hline Kezami -zuki $10 \mathrm{sec}$ & 15.7000 & .82327 & 17.2000 & 1.31656 & 9.55 \\
\hline Kezami-mwashi $15 \mathrm{sec}$ & 9.5000 & .52705 & 11.3000 & .67495 & 18.95 \\
\hline Ura-nwashi $15 \mathrm{sec}$ & 7.7000 & .48305 & 9.8000 & .91894 & 27.27 \\
\hline Kzami-gyaku $15 \mathrm{sec}$ & 10.8000 & .78881 & 11.9000 & .87560 & 10.19 \\
\hline Gyaku-kzami mwashi $15 \mathrm{sec}$ & 9.3000 & .48305 & 10.9000 & .87560 & 17.20 \\
\hline Gyaku-ura mwashi $15 \mathrm{sec}$ & 8.1000 & .31623 & 10.3000 & .67495 & 27.16 \\
\hline Kzami-ushiro-ura mwashi $15 \mathrm{sec}$ & 7.6000 & .51640 & 9.7000 & .48305 & 27.63 \\
\hline Gyaku - zuki 40sec & 32.3000 & 1.41814 & 34.0000 & 1.41421 & 5.26 \\
\hline Kezami-zuki $45 \mathrm{sec}$ & 33.1000 & 1.66333 & 34.7000 & 1.63639 & 4.83 \\
\hline Kezami-mwashi $45 \mathrm{sec}$ & 26.2000 & 1.31656 & 27.8000 & 1.54919 & 6.11 \\
\hline Ura-nwashi $45 \mathrm{sec}$ & 24.6000 & 1.57762 & 26.5000 & 1.50923 & 7.72 \\
\hline Kzami-gyaku $45 \mathrm{sec}$ & 30.3000 & .82327 & 32.1000 & 1.19722 & 5.94 \\
\hline Gyaku-kzami mwashi 45 sec & 24.3000 & .94868 & 25.7000 & 1.41814 & 5.76 \\
\hline Gyaku-ura mwashi $45 \mathrm{sec}$ & 21.4000 & 1.07497 & 23.1000 & 1.19722 & 7.94 \\
\hline Kzami-ushiro-ura mwashi $45 \mathrm{sec}$ & 20.4000 & .96609 & 22.3000 & .94868 & 9.31 \\
\hline Reaction of complex skills & 1.2060 & .30725 & .8980 & .03967 & 34.30 \\
\hline Reaction of complex skills & 1.3960 & .30823 & .9270. & .03129 & 50.59 \\
\hline Reaction of complex skills & 1.2090 & .04864 & 1.3560 & .34945 & -10.84 \\
\hline Reaction of complex skills & 1.3230 & .05559 & 1.3440 & .32684 & -1.56 \\
\hline Special agility (right) & 12.5150 & a.67228 & 11.3930 & .53421 & 9.85 \\
\hline Special agility (lift) & 12.5860 &, 64574 & 11.0920 & .58069 & 13.47 \\
\hline
\end{tabular}

The light of the table the Mean and the Std. Deviation for the Before and After the implementation and the Ratio Change\% for the experimental group 
Table (2)

Significant differences between control group and experimental

\begin{tabular}{|c|c|c|c|c|c|c|}
\hline Variables & Group & $\mathrm{N}$ & Mean Rank & Sum of Ranks & $\mathrm{Z}$ & Sig. \\
\hline \multirow{2}{*}{ Gyaku -zuki 10sec } & Control & 10 & 5.65 & 56.50 & 3.720 & .000 \\
\hline & Experimental & 10 & 15.35 & 153.50 & & \\
\hline \multirow{2}{*}{ Kezami -zuki $10 \mathrm{sec}$} & Control & 10 & 7.25 & 72.50 & 2,548 & .011 \\
\hline & Experimental & 10 & 13.75 & 137.50 & & \\
\hline \multirow{2}{*}{ Kzami -mwashi $15 \mathrm{sec}$} & Control & 10 & 6.80 & 68.00 & $* 2,945$ & .004 \\
\hline & Experimental & 10 & 14.20 & 142.00 & & \\
\hline \multirow{2}{*}{ ura mwashi $15 \mathrm{sec}$} & Control & 10 & 6.00 & 60.00 & $* 3,562$ &, 000 \\
\hline & experimental & 10 & 15.00 & 150.00 & & \\
\hline \multirow{2}{*}{ Kzami-Gyaku 15sec } & control & 10 & 8.70 & 87.00 & 1.463 & .190 \\
\hline & experimental & 10 & 12.30 & 123.00 & & \\
\hline \multirow{2}{*}{ Gyaku-kzami mwashi $15 \mathrm{sec}$} & control & 10 & 9.00 & 90.00 & 1,212 & .280 \\
\hline & experimental & 10 & 12.00 & 120.00 & & \\
\hline \multirow{2}{*}{ Gyaku- ura mwashi $15 \mathrm{sec}$} & control & 10 & 7.20 & 72.00 & $* 2.690$ & .011 \\
\hline & experimental & 10 & 13.80 & 138.00 & & \\
\hline \multirow{2}{*}{ Kzami-ushiro-ura mwashi $15 \mathrm{sec}$} & control & 10 & 9.00 & 90.00 & 1.314 & .280 \\
\hline & experimental & 10 & 12.00 & 120.00 & & \\
\hline \multirow{2}{*}{ Gyaku - zuki 40sec } & control & 10 & 7.60 & 76.00 & 2.252 & .029 \\
\hline & experimental & 10 & 13.40 & 134.00 & & \\
\hline \multirow{2}{*}{ Kezami - zuki $45 \mathrm{sec}$} & control & 10 & 8.05 & 80.50 & 1.883 & .063 \\
\hline & experimental & 10 & 12.95 & 129.50 & & \\
\hline \multirow{2}{*}{ Kzami -mwashi $45 \mathrm{sec}$} & control & 10 & 9.00 & 90.00 & 1,174 & .280 \\
\hline & experimental & 10 & 12.00 & 120.00 & & \\
\hline \multirow{2}{*}{ ura mwashi $45 \mathrm{sec}$} & control & 10 & 9.45 & 94.50 & 0.830 & .436 \\
\hline & experimental & 10 & 11.55 & 115.50 & & \\
\hline \multirow{2}{*}{ Kzami-Gyaku 45sec } & control & 10 & 6.05 & 60.50 & $* 3,413$ & .000 \\
\hline & experimental & 10 & 14.95 & 149.50 & & \\
\hline \multirow{2}{*}{ Gyaku-kzami mwashi $45 \mathrm{sec}$} & control & 10 & 9.25 & 92.50 & ,976 &, 353 \\
\hline & experimental & 10 & 11.75 & 117.50 & & \\
\hline \multirow{2}{*}{ Gyaku- ura mwashi $45 \mathrm{sec}$} & control & 10 & 8,90 & 89.00 & 1.259 & .247 \\
\hline & experimental & 10 & 12.10 & 121,00 & & \\
\hline \multirow{2}{*}{ Kzami-ushiro-ura mwashi $45 \mathrm{sec}$} & control & 10 & 6.90 & 69.00 & 2.818 & .005 \\
\hline & experimental & 10 & 14.10 & 141.00 & & \\
\hline \multirow{2}{*}{ Reaction of complex skills } & control & 10 & 11.15 & 111.50 & .499 & .631 \\
\hline & experimental & 10 & 9.85 & 98.50 & & \\
\hline \multirow{2}{*}{ Reaction of complex skills } & control & 10 & 13.90 & 139.00 & 2.615 & .009 \\
\hline & experimental & 10 & 7.10 & 71.00 & & \\
\hline \multirow{2}{*}{ Reaction of complex skills } & control & 10 & 11.35 & 113,50 & .646 & .529 \\
\hline & experimental & 10 & 9.65 & 96,50 & & \\
\hline \multirow{2}{*}{ Reaction of complex skills } & control & 10 & 11.65 & 118,50 & .874 & .393 \\
\hline & experimental & 10 & 9.35 & 93,50 & & \\
\hline \multirow{2}{*}{ Special agility (right) } & Control & 10 & 13.65 & 136.50 & 2.382 &, 015 \\
\hline & Experimental & 10 & 7.35 & 73.50 & & \\
\hline \multirow{2}{*}{ Special agility (lift) } & Control & 10 & 13.60 & 136.00 & $* 2.345$ & .019 \\
\hline & Experimental & 10 & 7.40 & 74.00 & & \\
\hline
\end{tabular}

\section{$Z$ within $0.05=1.96$}

This table shows that there are statistically significant differences between the experimental group andcontroi group in variables of the research 
Table (3)

Significant differences between the before the experimental and after for the control group

\begin{tabular}{|c|c|c|c|c|c|c|}
\hline & & $\mathrm{N}$ & Mean Rank & Sum of Ranks & $\mathrm{Z}$ & Sig. \\
\hline \multirow{3}{*}{ Gyaku zuki $10 \mathrm{sec}$} & - & 0 & 0.00 & 0.00 & $-1.890 a$ & 0.06 \\
\hline & + & 4 & 2.50 & 10.00 & & \\
\hline & $=$ & 6 & & & & \\
\hline \multirow{3}{*}{ Kzami zuki $10 \mathrm{sec}$} & - & 0 & 0.00 & 0.00 & $-2.972 \mathrm{a}$ & 0.00 \\
\hline & + & 10 & 5.50 & 55.00 & & \\
\hline & & 0 & & & & \\
\hline \multirow{3}{*}{ Kzami mwashi $15 \mathrm{sec}$} & - & 0 & 0.00 & 0.00 & $-3.051 \mathrm{a}$ & 0.00 \\
\hline & + & 10 & 5.50 & 55.00 & & \\
\hline & $=$ & 0 & & & & \\
\hline \multirow{3}{*}{ Ura mwashi $15 \mathrm{sec}$} & - & 0 & 0.00 & 0.00 & $-3.162 \mathrm{a}$ & 0.00 \\
\hline & + & 10 & 5.50 & 55.00 & & \\
\hline & $=$ & 0 & & & & \\
\hline \multirow{3}{*}{ Kzami gyaku $15 \mathrm{sec}$} & - & 0 & 0.00 & 0.00 & $-2.972 a$ & 0.00 \\
\hline & + & 10 & 5.50 & 55.00 & & \\
\hline & $=$ & 0 & & & & \\
\hline \multirow{3}{*}{$\begin{array}{c}\text { Gyaku kzamimwashi } 15 \\
\text { sec }\end{array}$} & - & 0 & 0.00 & 0.00 & $-2.919 a$ & 0.00 \\
\hline & + & 10 & 5.50 & 55.00 & & \\
\hline & $=$ & 0 & & & & \\
\hline \multirow{3}{*}{$\begin{array}{c}\text { Gyaku ura mwashi } 15 \\
\text { sec }\end{array}$} & - & 0 & 0.00 & 0,00 & $-2.919 a$ & 0.00 \\
\hline & + & 10 & 5.50 & 55.00 & & \\
\hline & $=$ & 0 & & & & \\
\hline \multirow{3}{*}{$\begin{array}{l}\text { Kzami mwashi ura } \\
\text { mwashi } 15 \mathrm{sec}\end{array}$} & - & 0 & 0.00 & 0,00 & $-2.970 a$ & 0.00 \\
\hline & + & 10 & 5.50 & 55,00 & & \\
\hline & & 0 & & & & \\
\hline \multirow{3}{*}{ Gyaku zuki $40 \mathrm{sec}$} & - & 0 & 0.00 & 0,00 & $-1.732 \mathrm{a}$ & 0.08 \\
\hline & + & 3 & 2.00 & 6,00 & & \\
\hline & $=$ & 7 & & & & \\
\hline \multirow{3}{*}{ - Kzami zuki $40 \mathrm{sec}$} & - & 0 & 0.00 & 0,00 & $-2.000 \mathrm{a}$ & 0.05 \\
\hline & + & 4 & 2.50 & 10,00 & & \\
\hline & $=$ & 6 & & & & \\
\hline \multirow{3}{*}{ Kzami mwashi $45 \mathrm{sec}$} & $\square$ & 0 & 0.00 & 0,00 & $-1.732 \mathrm{a}$ & 0.08 \\
\hline & + & 3 & 2.00 & 6,00 & & \\
\hline & $=$ & 7 & & & & \\
\hline \multirow{3}{*}{ Ura mwashi $45 \mathrm{sec}$} & & 0 & 0.00 & 0,00 & $-2.000 \mathrm{a}$ & 0.05 \\
\hline & + & 4 & 2.50 & 10.00 & & \\
\hline & & 6 & & & & \\
\hline \multirow{3}{*}{ Kzami gyaku $45 \mathrm{sec}$} & - & 1 & 2.00 & 2.00 & $-.577 \mathrm{a}$ & 0.56 \\
\hline & + & 2 & 2.00 & 4.00 & & \\
\hline & & 7 & & & & \\
\hline \multirow{3}{*}{ Reaction complex skills } & - & 0 & 0.00 & 0.00 & $-2.449 a$ & 0.01 \\
\hline & + & 6 & 3.50 & 21.00 & & \\
\hline & $=$ & 4 & & & & \\
\hline \multirow{3}{*}{ Reaction complex skills } & & 0 & 0.00 & 0.00 & $-3.000 \mathrm{a}$ & 0.00 \\
\hline & + & 9 & 5.00 & 45,00 & & \\
\hline & $=$ & 1 & & & & \\
\hline \multirow{3}{*}{ Reaction complex skills } & - & 0 & 0.00 & 0.00 & $-3.000 \mathrm{a}$ & 0.00 \\
\hline & + & 9 & 5.00 & 45.00 & & \\
\hline & $=$ & 1 & & & & \\
\hline \multirow{3}{*}{ Reaction complex skills } & - & 10 & 5.50 & 55.00 & $-2.810 b$ & 0.00 \\
\hline & + & 0 & 0.00 & 0.00 & & \\
\hline & $=$ & 0 & & & & \\
\hline & - & 10 & 5.50 & 55.00 & $-2.803 b$ & 0.01 \\
\hline Special agility (right) & + & 0 & 0.00 & 0.00 & & \\
\hline & $=$ & 0 & & & & \\
\hline & - & 6 & 4.00 & 24.00 & $-.357 \mathrm{a}$ & 0.72 \\
\hline Special agility (lift) & + & 4 & 7.75 & 31.00 & & \\
\hline & & 0 & & & & \\
\hline
\end{tabular}

$Z$ within $0.05=1.96$

This table shows that there are statistically significant differences between the before the and after experimental for the control group in variables of the research 


\section{Conclusions}

In the light of the methodology of the research, the sample, the objectives, the assumptions and the tools used, and based on the procedures implemented and the statistical analysis of data as well as the interpretation of the findings, the researcher could point out the following conclusions:

1. The practice program oriented towards developing the attack and indirect counterattack showed a positive and indicative statistical effect in improving the skills' performance effectiveness of the Kumite players;

2. The practice program oriented towards developing some physical fitness elements related to attack and indirect counter-attack skills showed a positive and indicative statistical effect in increasing the skills' performance effectiveness of the Kumite players;

3. The empirical group subject to the suggested practice program [attack and indirect counterattack) was preeminent compared to the adjusting group that used the traditional program in terms of the use of attack and direct and indirect counter-attack skills and some elements of the special physical fitness and performance effectiveness;

4. The traditional program oriented towards the development of the attack and direct counterattack showed a positive indicative statistical effect of attack and direct counter-attack as well as some elements of special physical fitness and the performance effectiveness, yet at less rates than those resulting from the suggested practice program for the empirical group.

5. The suggested practice program showed an actual improvement in the rate of use by the players of the attack and the individual and complex indirect counter-attack in view of the pre- and post-measurement in the interest of the post-measurement;

6. The suggested practice program, by using the attack and indirect counter-attack in the attack and counter-attack skills, showed an improvement in the performance effectiveness between the empirical and the adjusting groups in terms of the post-measurement in the interest of the empirical group;
7. The suggested practice program showed an improvement in the increase of effectiveness of some tactical sets for attack and indirect counter-attack by using the space of the court moves - tactical sets - skill sets (individual complex] - match time - tricks recommendations for attacks - managing the match] favouring the post-measurement for the empirical group.

\section{Recommendations}

With due respect to the data, key findings and conclusions of the research, and according the sample of the research and the fields thereof, the following recommendations may be submitted:

1. Focus on the special physical aspect, being the development of the strength element in terms of speed, endurance, reflex and special fitness (moves of the feet, chicanery and tricks);

2. Focus on the skills' aspect (individual complex) to optimize the skills resultant of the players by using such skills in attack and counter-attack, and make sure the player masters such skills well;

3. Focus on the tactical aspect through (moves distance during the game - timing of attack chicanery and tricks - time of the match - direct and indirect attack) in order to optimize the tactical resultant of the players;

4. Permanent and continuous analysis of local and international matches to identify the best methods used in the game, and the most used attack and indirect counter-attack skills, both individual and complex, throughout the game;

5. Focus on the tactical skills' aspect in educating and training the players, especially junior players, and use of different methods to ensure the performance effectiveness of the game tactical skills and, accordingly, win the game;

6. Focus on developing practice programs similar to the development of tactical skills' performance (attack and counter-attack) for other samples (juniors - youth), taking into account the special characteristics of each age bracket. 


\section{References}

1. Ebrahim alebiary ( 2003 ): Developing some attack tactics and its effect on the matches results for the karate juniors.magester. faculty of physical education. menoufia university

2. ( 2007): designing a tacteks systems for penetiating the mealn of competitor, and its effecton the effectiveness of performance for karate players .phd thesis . faculty of physical education. menuofia university

3. Hamilton roschel,etc ( 2009 ): School of physical education and sports, university of sae Paulo, Brazilian karate federation, brazil

4. Mohamed abd elrahman (2009 ): The effect of developing special agility through foot movment on the improvement of the effectiveness performance some of attack skills . magester. faculty of physical education. Alexandria university

5. Mohamed ramzy ( 2011): Effect of some drills for neuromusculer co- ordination upon effectiveness of skills performance for kumite players. Magester facultyof physical education. mansoura university.

6. Mohamed said abo elnour (2002): Effectiveness developing of movment attack skills at matches results for karate players. Magester. Faculty of physical education. zagazeg university.

7. Mohamed samir elsbahy (2005): the effect of training program for some of defence style at matches results for karate players. Magester. Faculty of physical education. Tanta university.

8. Mahmoud elbeshehy (2005): The effects of training program of the strategy and skillfull characteristics according to the strategy of level and results sports achivied i karate .phd. faculty of physical education . helwan university

9. Said gameel (2010) -.Effect of developing complex motor skills on technical performance effectiveness of junior boxers. Phd. Faculty of physical education. mansoura university.

10. Sherif elawdey, Omar labib (2004) :Basics of attack, kumite

11. www.seido.co.uk

12. www.sportsci.org

13. www.sportscoach-sci.com

14. www.24fightingchickens.com

15. www.karate-sci.com 